\title{
Modulation of oxidative stress mediators in the liver of adjuvant induced arthritic rats by Nyctanthes arbor tristis
}

\author{
Harsha Lad and Deepak Bhatnagar ${ }^{*}$
}

\begin{abstract}
Background: Oxidative stress is found as one of the causes in various pathological conditions. It has been proven in many studies that medicinal plants have antioxidant constituents that help in coping with the oxidative stress. Therefore, the present study aimed at evaluating the antioxidant effects of Nyctanthes arbor tristis leaves extract on the liver of Freund's complete adjuvant (FCA) induced arthritis (RA) rat model.

Methods: The hydroethanolic extract of N. arbor tristis leaves (NATE) was evaluated for its phytoconstituents and in vitro antioxidant activity such as free radical scavenging activity (FRSA), metal chelation activity (MCA), reducing power (RP) and plasmid nicking assay. Effects of NATE treatment on the oxidative stress markers along with histopathology of liver in arthritic rats were studied.

Results: The results revealed the presence of phenolic, triterpenoid and flavonoid compounds in hydroethanolic extract of $\mathrm{N}$. arbor tristis, which were strongly and positively correlated with the antioxidant activities. NATE significantly modulated oxidative stress markers of liver in favor of reducing the oxidative stress.

Conclusion: It is concluded that increased oxidative stress in liver of FCA induced arthritis mitigated by NATE treatment by strengthening the intracellular antioxidant defense. The study suggests that the leaves of N. arbor tristis possess a notable amount of the phytoconstituents which are responsible for its antioxidant effects. The study has provided information about the antioxidant activity of $\mathrm{N}$. arbor tristis, which will be useful to develop pharmaceuticals for the treatment of arthritis.
\end{abstract}

Keywords: Nyctanthes arbor tristis, Freund's complete adjuvant, Phytoconstituents, Antioxidant, Plasmid nicking assay

\section{Background}

Oxidative stress is the result of imbalance between the generation of reactive oxygen and nitrogen species (ROS and RNS) and the capacity of intracellular antioxidant defense to neutralize them. These are highly reactive and transient species, which include super oxide radical $\left(\mathrm{O}_{2}{ }^{-}-\right)$, hydroxyl radical $\left(\mathrm{OH}^{*}\right)$, hydrogen peroxide $\left(\mathrm{H}_{2} \mathrm{O}_{2}\right)$, nitric oxide radical $\left(\mathrm{NO}^{\circ}\right)$ and many others are generated from the interaction of these species with other radicals or molecules [1]. The excessive generation of these reactive species beyond the capacity to neutralize them can alter the intracellular homeostasis and oxidatively modify various biomolecules such as

\footnotetext{
* Correspondence: deepakbioch@yahoo.co.in

School of Biochemistry, Devi Ahilya University, Khandwa Road, Indore 452001, M.P., India
}

lipids, proteins and nucleic acids. The oxidative modification results in the alteration of their biological functions leading to various diseases such as cancer, neurodegenerative and inflammatory diseases, including rheumatoid arthritis (RA). These species are formed during various metabolic reactions such as in the electron transport chain during aerobic oxidation, phagocyte activation during inflammation and other reactions. To combat with such oxidative alterations, the cells are equipped with an intracellular antioxidant defense, which includes various enzymes such as super oxide dismutase (SOD), glutathione peroxidase (GSH-Px), catalase (CAT) and molecules such as glutathione (GSH) that help in removing such reactive species and maintains intracellular redox status [2]. The oxidation of lipid molecules if not stopped by antioxidants; may initiate a 
chain of oxidation of molecules known as lipid peroxidation (LPO). Malondialdehyde (MDA) the end product of LPO, may interact and crosslink with various biomolecules and damage them [3]. Elevated level of MDA with altered activity of oxidative enzyme and antioxidant level was observed in RA sera and synovial fluids [4]. The ROS and inflammatory mediators generated at the site of inflammation may reach to other vital organs such as liver by systemic circulation and affect their normal functioning.

Antioxidant therapy has been shown to ameliorate the oxidative and arthritic changes [5]. The use of herbal plants and their active constituents in the management of various diseases has increased due to its medicinal importance, easy availability, less side effects and low cost. In the Indian medicinal system, a large number of herbal plants and their preparation have been reported for various medicinal usages. It is expected that phytochemicals with potential antioxidant activity may be used for the treatment of diseases in which oxidative stress is one of the causes.

Nyctanthes arbor-tristis is a common ornamental plant of family oleacea and different parts of the plants are used in traditional medicines in India. $N$. arbor-tristis showed the presence of phytosterols, phenolics, tannins, flavonoids, glycosides and saponins with glycosides and alkaloids. Iridoid glycosides in the leaves showed antiinflammatory and anti-pyretic activities [6]. Various biological activities have been shown in the leaves of $N$. arbor-tristis such as anti-arthritic, hepatoprotective, anti-leishmanial, anti-viral, and anti-fungal activities, as well as analgesic, antipyretic and ulcerogenic activities $[7,8]$. In the present study, $N$. arbor-tristis (NATE) was evaluated for its antioxidant effects on the liver of FCA induced arthritic rats. This might be the first report on the effects of $N$. arbor-tristis on the liver antioxidant status in experimental arthritis.

\section{Methods}

\section{Chemicals}

Ursolic acid, quercitrin hydrate, 1,1,3,3 tetraethoxypropane (TEP), 1-chloro, 2, 4 dinitrobenzene (CDNB), 2, 2diphenyl-1-p-picryl hydrazyl (DPPH) were purchased from Sigma and Aldrich Co. (St. Louis, MO, USA), while Freund's Complete Adjuvant (FCA) was procured from Difco Laboratories, Detroit, Michigan, USA. Ethanol, Folins Ciocalteau reagent, trichloroacetic acid (TCA) and HPLC grade acetonitrile were purchased from Merck Chemicals, Mumbai, India. Butylated hydroxy toluene (BHT), ferrozine, pyrogallol, ethylenediamine tetracitic acid (EDTA) and other chemicals and solvents of $A R$ grade were purchased from $\mathrm{Hi}$ Media Co. Mumbai, India.

\section{Preparation of the extract}

The extract of $N$. arbor tristis (NATE) was prepared by adding $1 \mathrm{~g}$ powder of dried leaves in $25 \mathrm{ml}$ of ethanol: water $(1: 1)$ at room temperature and kept overnight in the dark. The mixture was centrifuged at $13,000 \times \mathrm{g}$ for $45 \mathrm{~min}$. Supernatant obtained was evaporated at room temperature and the yield was calculated. The yield of hydroethanolic extract of $N$. arbor tristis leaves was $24 \%(\mathrm{w} / \mathrm{w})$. The extractable compound was dissolved in $50 \%$ ethanol and used as a test sample for further examination.

\section{Phytoconstituents}

The total phenolic, flavonoid and terpenoid content of NATE was determined as described earlier in Lad et al. [9]. Briefly, the total phenolic compounds were estimated using the Folin-ciocalteu reagent and amount of phenolic compounds was calculated using propyl gallate $(1 \mathrm{mg} / \mathrm{ml}$ in distilled water) as standard. Total triterpenoid content (TTC) was estimated using ursolic acid ( $1 \mathrm{mg} / \mathrm{ml}$ in methanol) as standard. To determine the total flavonoid content (TFC), the aluminium chloride method was followed and quercitrin hydrate $(1 \mathrm{mg} / \mathrm{ml}$ in ethanol) was used as standard.

\section{In vitro antioxidant activity}

Free radical scavenging activity (FRSA) using DPPH, metal chelation activity (MCA) and reducing power of NATE were measured by the method as described earlier [9]. Briefly, The FRSA is based on the reduction of DPPH by the reductants present in the test sample and the decrease in DPPH absorption at $517 \mathrm{~nm}$ was measured after $10 \mathrm{~min}$ using butylated hydroxyl toluene $(\mathrm{BHT})$ as a reference compound. The chelation of $\mathrm{Fe}^{2+}$ by the extract was measured and expressed as \% metal chelation activity using EDTA as a reference compound. The reduction of $\mathrm{FeCl}_{3}$ in the presence of test sample was measure of reducing ability.

\section{Plasmid nicking assay}

The inhibition of hydroxyl radical induced DNA damage in presence of the extract was measured by the method as described in Lad et al. [9]. Briefly, the native conformation of plasmid DNA (pBR 322) is supercoiled form, which turns into open circular or nicked form in the presence of an oxidizing agent. The inhibition of hydroxyl radical induced DNA damage in presence of the extract is a measure of antioxidant activity. The plasmid DNA $(1 \mu \mathrm{g})$ was incubated with two different concentrations of NATE $(25$ and $50 \mu \mathrm{g}$ ) and Fenton's reagent $\left(23 \mu \mathrm{M}\right.$ of $\mathrm{H}_{2} \mathrm{O}_{2}, 376 \mu \mathrm{M}$ of ascorbic acid and $600 \mu \mathrm{M}$ of $\mathrm{FeCl}_{3} \cdot 6 \mathrm{H}_{2} \mathrm{O}$ ). The reaction mixture was incubated for $45 \mathrm{~min}$ at $37{ }^{\circ} \mathrm{C}$. BHT $(50 \mu \mathrm{g})$ was used as a positive control. After incubation, samples were mixed with $5 \mu \mathrm{l}$ 
of loading dye and electrophoresed in 1\% agarose gel containing ethidium-bromide $(5 \mu \mathrm{g} / \mathrm{ml})$ by using a 1X TAE buffer, $\mathrm{pH}$ 8. Ethidium-bromide stained DNA bands were visualized and recorded in gel documentation system.

\section{Correlation}

The correlation coefficient between the phytoconstituents and various antioxidant properties were determined.

\section{Toxicity study and dose selection}

Albino Wistar rats of both the sex, weighing in the range of $150-180 \mathrm{gm}$ were divided into five groups having three rats in each group. Increasing doses such as $0.0,1.0,2.0,3.0$ and $5.0 \mathrm{~g} / \mathrm{kg}$ body weight of $N$. arbor tristis leaves extract (NATE) were orally administered to different groups of rats and were critically observed for clinical signs, gross behavioral changes and mortality up to $72 \mathrm{~h}$ period as per OECD guidelines. Rathod et al., [10] showed dose dependent in vivo antioxidant potential of Nyctanthes arbor tristis leaves (50, 100 and $200 \mathrm{mg} / \mathrm{kg}$ body wt.). The dose of $200 \mathrm{mg} / \mathrm{kg}$ was found to be more effective therefore, was also selected for the present study.

\section{Animals and induction of arthritis}

Male albino rats of Wistar strain weighing 180-200 g were used in the study. Rats were housed in polypropylene cages with six animals per cage and maintained under standard laboratory conditions [temperature $(25 \pm 2){ }^{\circ} \mathrm{C}$ and relative humidity $50 \pm 4 \%$ ] with dark and light cycle $(12 / 12 \mathrm{~h})$ and had free access to diet and drinking water. The experiments were conducted in accordance with the guidelines of the Institutional Animal Ethics Committee (No. Biochem/01/2013-14). Freund's complete adjuvant (FCA, $10 \mathrm{mg} / \mathrm{ml}$ ) was used to induce experimental arthritis. FCA $(0.1 \mathrm{ml})$ was subcutaneously injected to the plantar surface of right hind paw of the rats. The rats in which inflammation was consistent up to day 14 of arthritis induction were selected for further studies. Four replicates of six animals in each group (24 rats in each group) were grouped as follows:

Group 1: Control (Ethanol: water (1:1), $2.5 \mathrm{ml} / \mathrm{kg}$ body weight $[\mathrm{Bw}])$.

Group 2: FCA injected arthritic rats

Group 3: FCA injected arthritic rats + indomethacin

(10 mg/kg Bw/day, p. o. by gavage) from day 15 to day 28 of arthritis induction.

Group 4: FCA injected arthritic rats + NATE $(200 \mathrm{mg} / \mathrm{kg}$

Bw/day, p. o. by gavage) from day 15 to day 28 of arthritis induction.

\section{Collection of biological samples and preparation for tissue homogenate}

The animals were sacrificed by cervical dislocation on day 29 and the liver was removed immediately and washed with ice cold $0.1 \mathrm{M}$ phosphate buffered saline (PBS, 1:9), $\mathrm{pH}$ 7.4. A small piece of liver was fixed in $10 \%$ formalin for histopathology. The tissue was blotted dry, weighed and minced to prepare tissue homogenate. A $10 \%$ tissue homogenate was prepared in 0.1 M PBS using Potter-Elvehjem Homogenizer (Remi, Mumbai, India) followed by centrifugation at $16,000 \times \mathrm{g}$ for $25 \mathrm{~min}$ at $4{ }^{\circ} \mathrm{C}$. The supernatant obtained was immediately used for the antioxidant enzyme assay, GSH and carbonyl content.

\section{Histopathology}

Histopathology was performed to study the effect on the cellular architecture of the liver in arthritic and treated rats. The haemotoxylin and eosin $(\mathrm{H}$ and $\mathrm{E})$ stained sections were visualized under a light microscope (Nikon eclipse 50i, Japan) under 20X.

\section{Assay for lipid peroxidation}

Lipid peroxidation (LPO) in liver was determined by measuring malondialdehyde (MDA) content using HPLC (Younglin, Korea). The conditions for HPLC were similar as described by Tukozkan et al. [11]. The MDA peak was identified and quantified in the samples using standard calibration curve obtained from 1,1,3,3 tetraethoxypropane (TEP), using the linear regression equation derived from the peak area and expressed as nmol $\mathrm{MDA} / \mathrm{mg}$ protein.

\section{Assay of antioxidant enzymes}

The antioxidant enzyme activity, GSH and carbonyl content were measured according to the method as described earlier in Lad et al. [12]. The ability of the enzyme to inhibit the autoxidation of pyrogallol in the presence of EDTA was used as a measure of SOD activity at $340 \mathrm{~nm}$. The decomposition of hydrogen peroxide was used to measure catalase activity. The method for the estimation of glutathione-S-transferase (GST) activity was based on the property of conjugation of $-\mathrm{SH}$ group with 1-chloro 2, 4-dinitrobenzene (CDNB) mediated by GST. Estimation of tissue glutathione (GSH) was based on the development of a relatively stable yellow color with 5, 5'-dithio-bis-2, nitrobenzoic acid (DTNB) with GSH. Protein carbonyl content in liver was determined after derivatisation with 2, 4 - dinitrophenyl hydrazine (DNPH) and measured at $370 \mathrm{~nm}$ using molar absorption coefficient of $22,000 \mathrm{M}^{-1} \mathrm{~cm}^{-1}$. 


\section{Statistical analysis}

The data obtained was analyzed by one-way analysis of variance (ANOVA) followed by the Tukey's (HSD) test using SPSS version 20.0 to calculate interrelation between the groups. The correlation was calculated using Pearson's correlation coefficient.

\section{Results}

Phytochemical screening

The total phenolic, triterpenoid and flavonoid contents of NATE were determined. The phenolic, triterpenoid and flavonoid contents were $29.74 \pm 0.13 \mathrm{mg}$ of gallic acid equivalent (GAE)/g of extractable compound, $184.43 \pm 1.13 \mathrm{mg}$ ursolic acid equivalent (UAE)/g of extractable compound and $162.13 \pm 1.52 \mathrm{mg}$ quercitrin hydrate equivalent (QHE)/g of extractable compound respectively (Table 1 ).

\section{In vitro antioxidant activity}

NATE was screened for its in vitro antioxidant activity using various in vitro assays. The extract showed a concentration dependent increase in FRSA, MCA and RP (Fig. 1a-c).

\section{Plasmid nicking assay}

The Fenton's reagent mediated plasmid DNA damage was assessed with and without extract (Fig. 2). The native confirmation of plasmid DNA pBR322 was supercoiled form (Fig. 2, Lane 1). The hydroxyl radicals generated in Fenton's reaction caused DNA damage as evidenced by transforming its native supercoiled form to open circular or linear form (Lane 2). The result of the plasmid nicking assay showed that in the presence of BHT (Lane 3, $50 \mu \mathrm{g}$ ) and NATE (Lane 4 and 5; 25 and $50 \mu \mathrm{g}$ respectively), the native supercoiled form was retained. The protection provided by NATE was concentration dependent and was comparable with BHT.

\section{Correlation study}

The results showed a strong and positive correlation between the phytoconstituents and the antioxidant properties (Table 2).

Table 1 Estimation of total phenolic, triterpenoid and flavonoid content of NATE

\begin{tabular}{lr}
\hline Constituents & \multicolumn{1}{c}{ Content } \\
\hline Total phenolic conntent $^{\mathrm{a}}$ & $29.74 \pm 0.13$ \\
Total triterpanoid content $^{\mathrm{b}}$ & $184.43 \pm 1.13$ \\
Total flavonoid content $^{\mathrm{c}}$ & $162.13 \pm 1.52$ \\
\hline
\end{tabular}

Values are mean \pm SE of four replicates

$\mathrm{a}=\mathrm{mg}$ of gallic acid equivalent $/ \mathrm{g}$ extractable compound

${ }^{b}=m g$ of ursolic acid equivalent/g extractable compound

${ }^{c}=\mathrm{mg}$ of quercitrin hydrate equivalent $/ \mathrm{g}$ extractable compound

\section{Toxicity study}

The result of toxoicity study showed no toxic or deleterious effects upto $5.0 \mathrm{~g} / \mathrm{kg}$ oral dose. As the rats were administered the maximal possible dose, the LD50 value of NATE could not be determined.

\section{Determination of LPO}

The results showed that MDA content was significantly higher in FCA induced arthritic rats (Table 3; Group 2) as compared to control (Group 1). A significant reduction in MDA level was observed after indomethacin (Group 3) and NATE (Group 4) administration when evaluated against arthritic control (Group 2) and was comparable to control (Group 1).

\section{Determination of antioxidant enzyme activities}

The decrease in liver SOD, CAT and GST activities was significant in arthritic animals (Table 3; Group 2) as compared to control rats (Group 1). The SOD and GST activity was found to increase after indomethacin and NATE treatment (Group 3 and 4) with respect to arthritic group (Group 2) and was comparable with control (Group 1). The increase in liver CAT activity was not significant in indomethacin and NATE treated rats (Group 3 and 4) as compared to control (Group 1) and arthritic group (Group 2).

The results showed that liver GSH content was not significantly decreased in arthritic rats (Table 3; Group 2) as compared to control (Group 1). Treatment with indomethacin (Group 3) and NATE (Group 4) significantly increased the GSH content as compared to arthritic rats (Group 2) and was comparable with the control (Group 1).

The liver carbonyl content was significantly elevated in arthritic group (Table 3; Group 2) as compared to control (Group 1). The carbonyl content was significantly decreased by indomethacin and NATE treatment (Group 3 and 4) as compared to arthritic rats (Group 2).

\section{Effect on histopathology of liver in arthritic and treated groups}

The animals from control group (Fig. 3a) showed the normal cellular structure of liver at centrilobular zone. In contrast to this, the liver from the arthritic group (Fig. 3b) showed anomalous changes in cellular morphology when compared to control. The histology of liver from FCA induced animals revealed moderate microvesicular fatty changes, with sinusoidal congestion and infiltration of mononuclear cells. Indomethacin treatment also showed sinusoidal congestion with microvesicular fatty changes as compared to control (Fig. 3c). NATE treatment (Group 4) protected normal cellular characteristics of liver by reducing fatty changes and 

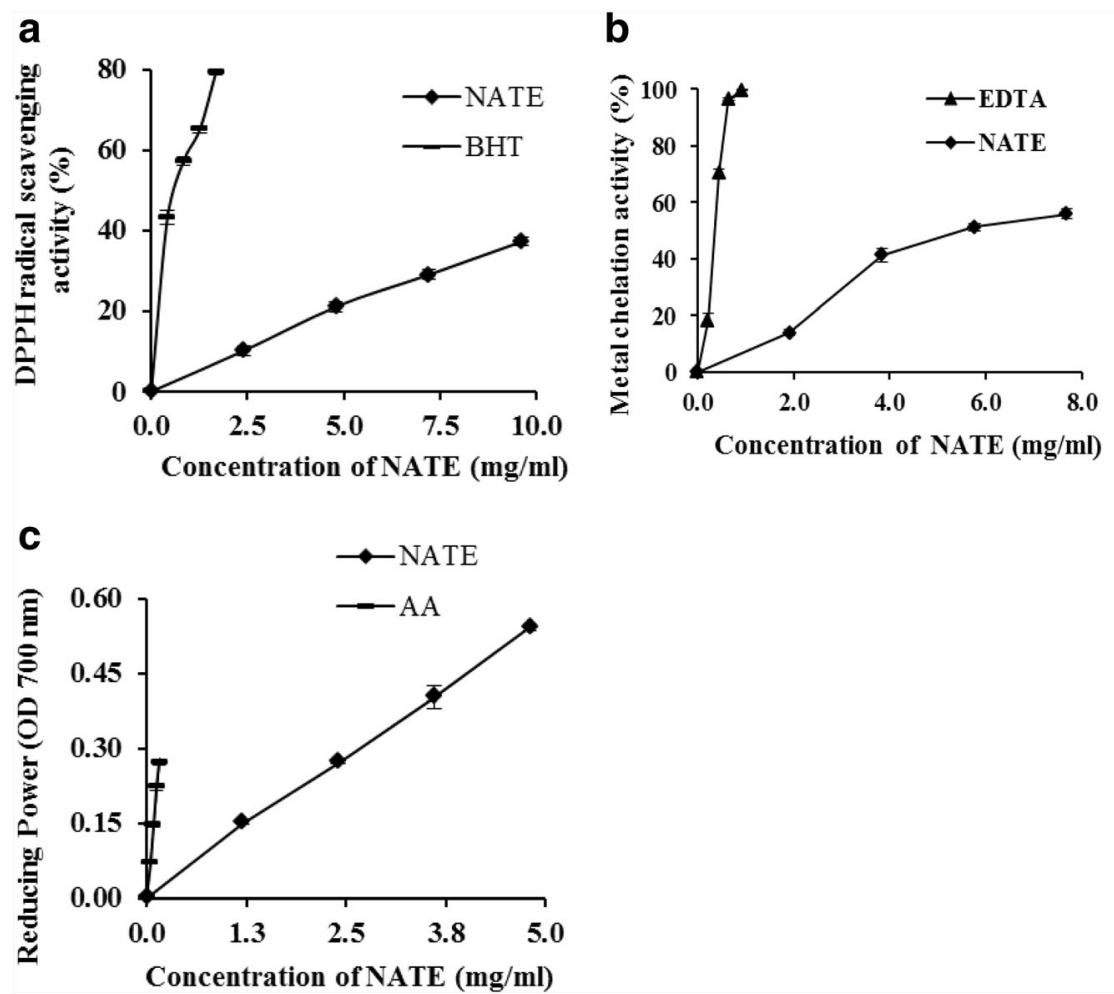

Fig. 1 Effects of different concentrations of NATE on (a) DPPH radical scavenging activity; (b) Metal chelation activity; (c) Reducing power. Values are Mean \pm SE of 4 replicates. All experimental values were significant at $P<0.05$ as compared to controls

sinusoidal congestion with mild mononuclear cell infiltration (Fig. 3d).

\section{Discussion}

Free radical mediated oxidative stress due to the compromised intracellular antioxidant defense has been one of the causing factors behind the etiology of a wide range of clinical disorders. Therefore, limiting the free radical generation or scavenging them may serve as a useful means in the therapy of various diseases. Antioxidant therapy may be useful in this regard and have shown promising results [5]. The use of antioxidants from natural sources will help to combat the diseases and to develop new therapeutic candidate.
In the present study, phytochemical analysis of NATE revealed the presence of phenolic, triterpenoid and flavonoid content. In an earlier study, the total phenolic and flavonoid content of $N$. arbor trisitis leaves $98.56 \pm 0.46 \mathrm{mg} / \mathrm{g}$ and $34.51 \pm 0.45 \mathrm{mg} / \mathrm{g}$ respectively was reported [13]. The difference in the amount of phytoconstituents in the present study was due to the difference in solvent and the extraction procedure. These compounds are potent antioxidants that can donate hydrogen to free radicals and thus break the chain reaction of lipid oxidation at the initiation step. The TPC and TFC exhibit redox properties due to the presence of polyphenolic groups that allow them to act as reducing agents, hydrogen donors and singlet oxygen quenchers and can be used as important

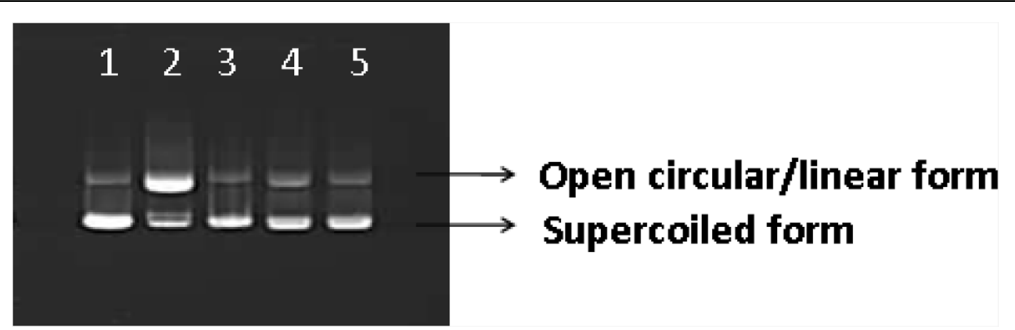

Fig. 2 Plasmid nicking assay Lane 1: DNA; Lane 2: DNA + Fenton's reagent; Lane 3: DNA + BHT (50 $\mu \mathrm{g})+$ + Fenton's reagent; Lane 4: DNA + NATE $(25 \mu \mathrm{g})+$ Fenton's reagent; Lane 5: DNA + NATE $(50 \mu \mathrm{g})+$ Fenton's reagent 
Table 2 Correlation coefficient between phytoconstituents and antioxidant properties of NATE

\begin{tabular}{lccc}
\hline $\begin{array}{l}\text { Antioxidant properties } \\
\text { Phyto-Constituents }\end{array}$ & FRSA & MCA & RP \\
\hline TPC & $1.00^{*}$ & $0.967^{*}$ & $0.995^{*}$ \\
TFC & $0.998^{*}$ & $0.967^{*}$ & $0.995^{*}$ \\
TC & $0.998^{*}$ & $0.967^{*}$ & $0.995^{*}$ \\
\hline FRSA Free radical scavenging activity & & \\
$\begin{array}{l}\text { MCA Metal chelation activity } \\
\text { RP Reducing power }\end{array}$ & \\
${ }^{*}$ Correlation coefficient is significant at $P<0.05$ & &
\end{tabular}

indicators of the antioxidant capacity [14]. These polyphenols have been found to associate with several health benefits [15].

The DPPH has been used to evaluate the antioxidant activity of the test sample. It is evident that the hydrogen donating ability of a substance is responsible for its free radical scavenging activity (FRSA). The result of the DPPH assay suggested that NATE possessed FRSA, which may contribute to its in vivo antioxidant potential as has also been reported by Balasundari et al. [16]. The polyphenolic compounds exhibit antioxidant activity by forming a metal ion complex, thus inhibiting the free metal ion induced radical generation [17]. The reducing power measures the ability of the antioxidant to donate electron to reduce $\mathrm{Fe}^{3+}$ to $\mathrm{Fe}^{2+}$. The reports suggested that the plant extract with greater TPC was associated with their reducing power [18]. The reducing power of NATE is suggested to be due to the presence of flavonoids and phenolic acids, capable of reducing $\mathrm{Fe}^{3+}$ to $\mathrm{Fe}^{2+}$. The reducing ability of the extract is found to associate with the presence of reductones that is supposed to be responsible for antioxidant activity by donating a hydrogen atom thus interrupting the free radical chain reaction [19]. An earlier report by Savarimuthu et al [20] has shown the presence of various in vitro antioxidant activities in the leaf extract of $N$. arbor trisitis which is in agreement with the present study.
In a radical generating system the change in conformation of plasmid DNA from supercoiled to open circular or linear form is indicative of oxidative DNA damage, which was inhibited in the presence of a radical scavenger [21]. In the present study, the native conformation i.e. supercoiled form of DNA was retained in the presence of NATE in a concentration dependent manner, which was comparable to the protection provided by BHT. It indicated that NATE has ability to chelate free metal ions and to scavenge the free radicals and thus protected the DNA from oxidative damage, which can be attributed to its phytoconstituents. These antioxidant properties can be correlated with phytoconstituents such as total phenolic, flavonoid and triterpenoid content of the extract. The correlation study showed a strong and positive correlation between phytoconstituents and antioxidant properties. Various other studies have indicated a linear relationship between the major phytoconstituents such as total phenolic compounds and antioxidant activity $[9,22,23]$. A study on Chinese medicinal plants has also shown a positive correlation between antioxidant activity and total phenolic content [24].

Determination of acute toxicity is necessary to evaluate the toxic effects after oral administration of a single dose of the drug. NATE did not show any toxic or deleterious effects upto the dose of $5.0 \mathrm{~g} / \mathrm{kg}$ indicating low toxicity of the extract at high doses. As the rats were administered upto maximal possible dose, the LD50 value of NATE could not be determined, which is in agreement with the study reported by Bhalerao et al. [25].

In pathological conditions the balance between the free radical generation and the antioxidant activity is lost, resulting in oxidative damage to the cells and tissues. Though rheumatoid arthritis (RA) is an inflammatory disease of joints, its systemic effects have also been observed [26, 27]. Many reports showed the involvement of the liver in RA. The liver from adjuvant induced arthritis showed elevated oxygen uptake, decreased gluconeogenesis, increased glycolysis and reduced metabolism of xenobiotics $[28,29]$. It is known that activated

Table 3 Effect of NATE treatment on LPO, antioxidant enzymes, GSH and carbonyl content in the liver of FCA induced arthritic rats

\begin{tabular}{llllllll}
\hline Group & Treatments & $\mathrm{LPO}^{\mathrm{a}}$ & $\mathrm{SOD}^{\mathrm{b}}$ & $\mathrm{CAT}^{\mathrm{c}}$ & $\mathrm{GST}^{\mathrm{d}}$ & $\mathrm{GSH}^{\mathrm{e}}$ & Carbonyl $^{f}$ \\
\hline 1 & Control & $0.12 \pm 0.05$ & $15.05 \pm 1.18$ & $393.65 \pm 20.37$ & $0.86 \pm 0.09$ & $41.01 \pm 3.98$ & $1.78 \pm 0.42$ \\
2 & RA & $0.43 \pm 0.04^{*}$ & $8.31 \pm 0.37^{*}$ & $286.42 \pm 20.25^{*}$ & $0.57 \pm 0.05^{*}$ & $32.01 \pm 2.05^{\mathrm{NS}}$ & $4.40 \pm 0.22^{*}$ \\
3 & Indomet & $0.09 \pm 0.05^{\#}$ & $12.43 \pm 0.61^{\#}$ & $379.41 \pm 41.43^{\mathrm{NS}}$ & $0.94 \pm 0.07^{\#}$ & $44.76 \pm 0.92^{\#}$ & $2.25 \pm 0.09^{\#}$ \\
4 & NATE & $0.18 \pm 0.04^{\#}$ & $11.95 \pm 1.07^{\#}$ & $337.96 \pm 27.60^{\mathrm{NS}}$ & $0.98 \pm 0.10^{\#}$ & $41.13 \pm 1.82^{\#}$ & $1.70 \pm 0.19^{\#}$ \\
\hline
\end{tabular}

Values are Mean \pm SE of four replicates with six animals in each group

Groups 2, 3 and 4 as compared to Group 1. ${ }^{*} P<0.05$

Groups 3 and 4 as compared to Group 2. ${ }^{\#} P<0.05$; ${ }^{\text {NS }}$ Not significant

$\mathrm{a}=$ nmoles MDA formed $/ \mathrm{mg}$ protein

$\mathrm{b}=$ units $/ \mathrm{mg}$ protein

${ }^{c}=\mu$ moles $\mathrm{H}_{2} \mathrm{O}_{2}$ decomposed $/ \mathrm{min} / \mathrm{mg}$ protein

${ }^{\mathrm{d}}=\mu \mathrm{moles} \mathrm{GSH}$ conjugated $/ \mathrm{min} / \mathrm{mg}$ protein

$\mathrm{e}=\mu$ moles DTNB conjugated $/ \mathrm{mg}$ protein

${ }^{\mathrm{f}}=$ nmoles of carbonyl formed $/ \mathrm{mg}$ protein 

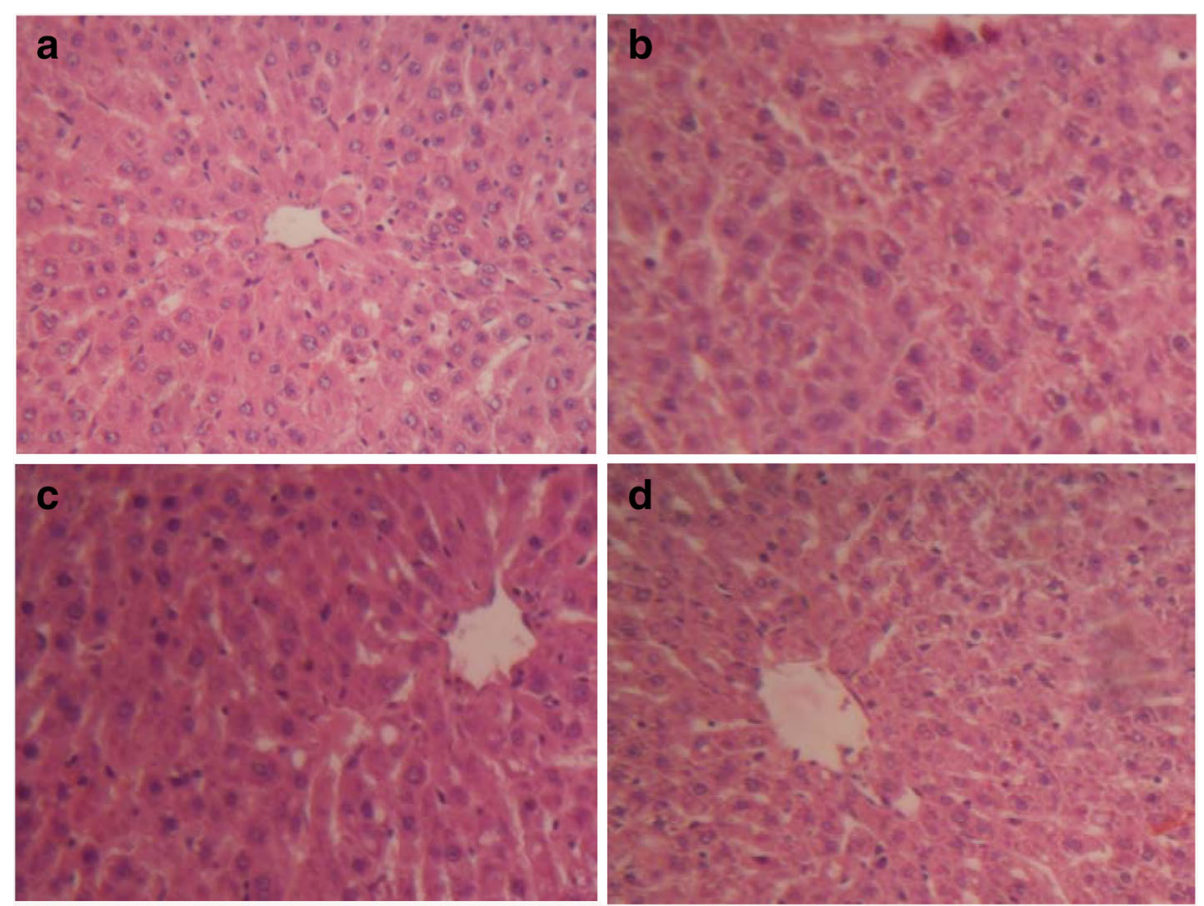

Fig. $3 \mathrm{H}$ and $\mathrm{E}$ stained section of liver from (a) control rats; (b) FCA induced arthritic rats; (c) FCA induced arthritic rats treated with Indomethacin $(10 \mathrm{mg} / \mathrm{kg})$ and $(\mathbf{d})$ FCA induced arthritic rats treated with NATE $(200 \mathrm{mg} / \mathrm{kg})$

inflammatory cells lead to ROS production in rheumatoid arthritis [30]. The tissue damage resulting from the inflammatory effects of RA might be due to increased LPO and prostaglandin synthesis [31]. The elevation of the MDA content may be the result of LPO, which is a free radical driven reaction that causes tissue membrane damage by reaction of oxygen with polyunsaturated fatty acids (PUFAs) [32]. Hsouna et al. [33] associated the reduced activity of antioxidant enzymes with the enhancement in the lipid peroxidation. In the present study, elevated levels of MDA in liver of arthritic animals have been observed, which might be due to tissue membrane damage. The treatment with NATE was found to inhibit LPO in arthritic animals, which gives evidence that NATE works as a strong antioxidant and plays an important role in improving free radical mediated tissue damage as indicated by reduced levels of MDA in liver of NATE treated group.

The inhibition of liver SOD may also be due to free radicals produced during the oxidative stress. However, if free radicals are not sufficiently scavenged by antioxidants, it may reduce the total antioxidant capacity in arthritic animals and lead to cellular injury. The increased activities of SOD in NATE treated animals may be a regulatory response to decreased oxidative stress. It has been shown that low SOD levels in RA patients, increased after NSAID treatment and reached normal levels [34]. The superoxide anions are dismutated by
SOD to form $\mathrm{H}_{2} \mathrm{O}_{2}$, which is decomposed by CAT [35]. The decrease in liver catalase activity may be due to its inactivation by $\mathrm{H}_{2} \mathrm{O}_{2}$. GSH in the liver has a redox system, which plays the first line of defense against various exogenous and endogenous compounds. GSH has an important role both as a substrate for glutathione peroxidase (GPx), glutathione reductase (GR) and cofactor for GST [36, 37]. There was a significant increase in GSH content of liver in arthritic rats after NATE treatment which was comparable to control. This may be due to the steady supply of GSH from the liver to other organs [38]. However, the activity of GST was found to significantly increase in NATE treated group, probably due to up regulation of GST by the phytoconstituents of NATE. The improved activity of antioxidant enzymes after NATE administration may be due to the free radical scavenging and reducing ability of the extract. Protein carbonyls are the most commonly used markers of protein oxidation and have been reported in many human pathologies $[39,40]$. It is suggested that the free radical scavenging and reducing power of NATE may minimize the oxidative effects on proteins.

The mild inflammatory and fatty changes in the liver of arthritic rats were in agreement with the study by Fernandes et al. [41]. The result suggests that NATE treatment showed recovery in the liver by controlling the infiltration of mononuclear cells and fatty changes. 


\section{Conclusion}

The results of the study suggest higher oxygen free radical production in the liver of arthritic animals as evidenced by increased MDA and carbonyl content with modulated antioxidant enzyme activity in RA. The present study revealed that the leaves of $N$. arbor tristis possessed potential antioxidant properties. It is suggested that treatment with $N$. arbor tristis strengthen the intracellular antioxidant defense by its antioxidant phytoconstituents to cope up with the free radical mediated oxidative stress in the liver of arthritic rats.

\section{Authors' contributions}

$\mathrm{HL}$ : designed and performed the experiments, participated in data analysis and manuscript preparation. DB: participated in study design and helped in manuscript preparation. Both authors read and approved the final manuscript.

\section{Competing interests}

Harsha Lad and Deepak Bhatnagar declare that they have no competing interests.

Received: 14 September 2016 Accepted: 15 December 2016

Published online: 04 January 2017

\section{References}

1. Conner EM, Grisham MB. Inflammation, free radicals, and antioxidants. Nutrition. 1996:12:274-7.

2. Valko M, Leibfritz D, Moncol J, Cronin MT, Mazur M, Telser J. Free radicals and antioxidants in normal physiological functions and human disease. Int J Biochem Cell Biol. 2007;39:44-84.

3. Comparti M. Biology of disease: lipid peroxidation and cellular damage in toxic liver injury. Lab Invest. 1985;53:599-623.

4. Ozturk HS, Cimen MY, Cimen OB, Kacmaz M, Durak I. Oxidant/antioxidant status of plasma samples from patients with rheumatoid arthritis. Rheumatol Int. 1999:19:35-7.

5. Jaswal S, Mehta HC, Sood AK, Kaur J. Antioxidant status in rheumatoid arthritis and role of antioxidant therapy. Clin Chim Acta. 2003;338:123-9.

6. Tuntiwachwuttikul P, Rayanil K, Taylor WC. Chemical constituents from the flowers of Nyctanthes arbor-tristis. Sci Asia. 2003;29:21-30.

7. Rathore B, Paul B, Chaudhary BP, Saxena AK, Sahu AP, Gupta YK. Comparative studies of different organs of Nyctanthes arbor tristis in modulation of cytokines in murine model of arithritis. Biomed Environ Sci. 2007:20:154-9.

8. Agrawal J, Pal A. Nyctanthes arbor-tristis Linn-a critical ethnopharmacological review. J Ethnopharmacol. 2013:46:645-58.

9. Lad H, Joshi A, Dixit D, Sharma H, Bhatnagar D. Antioxidant, genoprotective and immunomodulatory potential of Vitex negundo leaves in experimental arthritis. Orient Pharm Exp Med. 2016. doi:10.1007/s13596-016-0234-x.

10. Rathod N, Raghuveer I, Chitme HR, Chandra R. Free radical scavenging activity of Nyctanthes arbortristis in streptozotocin-induced diabetic rats. Indian J Pharm Educ Res. 2010;44:288-94.

11. Tukozkan N, Erdamar $\mathrm{H}$, Seven I. Measurement of total malondialdehyde in plasma and tissue by high performance liquid chromatography and thiobarbituric acid assay. Firat Tip Dergisi. 2006:11:88-92.

12. Lad H, Bhatnagar D. Amelioration of oxidative and inflammatory changes by Swertia chirayita leaves in experimental arthritis. Inflammopharmacology. 2016;24:363-75.

13. Narendhirakannan RT, Smeera T. In vitro anti-oxidant studies on ethanolic extracts of leaves and stems of arbor-tristis. L (Night-flowering Jasmine). Int J Biol Med Res. 2010;1(4):188-92.

14. Negri G, Teixeira EW, Alves MLTMF, Moreti ACCC, Otsuk IP, Borguini RG, Salatino A. Hydroxycinnamic acid amide derivatives, phenolic compounds and antioxidant activities of extracts of pollen samples from Southeast Brazil. J Agric Food Chem. 2011;59:5516-22.

15. Sunil C, Ignacimuthu S. In vitro and in vivo antioxidant activity of Symplocos cochinchinesis S. Moore leaves containg phenolic compounds. Food Chem Toxicol. 2011:49:1604-9.

16. Balasundari $P$, Singh SK, Kavimani S. Free radical scavenging of xanthones from Swertia chirata Buchham and tumor cell growth inhibition. Main Group Chem. 2005:4:177-85.
17. Laughton MJ, Halliwell B, Evans PJ, Robin J, Hoult S. Antioxidant and prooxidant actions of the plant phenolics quercetin, gossypol and myricetin. Biochem Pharmacol. 1987;36:717-20.

18. Sultana B, Anwar F, Przybylski R. Antioxidant activity of phenolic components present in barks of Azadirachta indica, Terminalia arjuna, Acacia nilotica and Eugenia jambolana Lam. trees. Food Chem. 2007;104:1106-14.

19. Yen GC, Chen HY. Antioxidant activity of various tea extracts in relation to their antimutagenicity. J Agric Food Chem. 1995;43:27-32.

20. Savarimuthu MJ, Kalirajan A, Padmalatha C, Ranjit Singh AJA. In vitro antioxidant evaluation and total phenolics of methanolic leaf extracts of Nyctanthes arbor-tristis L. Chin J Nat Med. 2013:11:0484-7.

21. Gandhi NM, Nair CKK. Radiation protection by Terminalia chebula: some mechanistic aspects. Mol Cell Biochem. 2005:277:43-8.

22. Hua BL, Wong CC, Cheng KW, Chen F. Antioxidant properties in vitro and total phenolic contents in methanol extracts from medicinal plants. LWT. 2008:41:385-90.

23. Mustafa RA, Hamid AA, Mohamed S, Bakar FA. Total phenolic compounds, flavonoids and radical scavenging activity of selected tropical plants. J Food Sci. 2010;75:C28-35

24. Yizhong C, Qiong L, Mei S, Harold C. Antioxidant activity and phenolic compounds of 112 traditional Chinese medicinal plants associated with anticancer. Life Sci. 2004;74:2157-84.

25. Bhalerao AR, Desai SK, Serathia BR, Vartak KM, Doshi GM. Antiarthritic studies on Nyctanthes arbor tristis and Maharasnadi ghan. Pharm Lett. 2011;3:101-10.

26. Haruna Y, Morita Y, Komai N, Yada T, Sakuta T, Tomita N, Fox DA, Kashihara N. Endothelial dysfunction in rat adjuvant-induced arthritis: vascular superoxide production by NADP $(\mathrm{H})$ oxidase and uncoupled endothelial nitric oxide synthase. Arthritis Rheum. 2006;54:1847-55.

27. Haruna Y, Morita Y, Yada T, Satoh M, Fox DA, Kashihara N. Fluvastatin reverses endothelial dysfunction and increased vascular oxidative stress in rat adjuvant-induced arthritis. Arthritis Rheum. 2007;56:1827-35.

28. Caparroz-Assef SM, Bersani-Amado CA, Nascimento EA, Kelmer-Bracht AM, Ishii-Iwamoto EL. Effects of the nonsteroidal anti-inflammatory drug nimesulide on energy metabolism in livers from adjuvant-induced arthritic rats. Res Commun Mol Pathol Pharmacol. 1998;99:93-116.

29. Fedatto Jr Z, Ishiii-Iwamoto $\mathrm{EL}$, Amado CB, Vicentini G, D'urso-Panerari A Bracht A, Kelmer-Bracht AM. Gluconeogenesis in the liver of arthritic rats. Cell Biochem Funct. 1999:17:271-8.

30. Fox DA. Etiology and pathogenesis of rheumatoid arthritis. In: Koopman WJ, Moreland LW, editors. Arthritis and allied conditions a textbook of rheumatology. 15th ed. Philadelphia, Lippincot: Williams and Wilkins; 2005. p. 1089-115.

31. Kalpakcioglu B, Senel K. The interrelation of glutathione reductase, catalase, glutathione peroxidase, superoxide dismutase and glucose-6-phosphatase in the pathogenesis of rheumatoid arthritis. Clin Rheumatol. 2008;27:141-5.

32. Kehrer JP. Free radicals are mediators of tissue injury and disease. Crit Rev Toxicol. 1993;23:21-48.

33. Hsouna AB, Saoudi M, Trigui M, Jamoussi K, Boudawara T, Jaoua S, Feki AE. Characterization of bioactive compounds and ameliorative effects of Ceratonia siliqua leaf extract against $\mathrm{CCl}_{4}$ induced hepatic oxidative damage and renal failure in rats. Food Chem Toxicol. 2011;49:3183-91.

34. Nivsarkar M. Improvement in circulating superoxide dismutase levels: role of non steroidal anti-inflammatory drugs in rheumatoid arthritis. Biochem Biophys Res Commun. 2000;270:714-6.

35. Fridovich I. The biology of oxygen radicals. Science. 1978;201:875-80.

36. Hassan MQ, Hadi RA, Al-Rawi ZS, Padron VA, Stohs SJ. The glutathione defense system in the pathogenesis of rheumatoid arthritis. J Appl Toxicol. 2001:21:69-73.

37. Hayes JD, McLellan LI. Glutathione and glutathione-dependent enzymes represent a co-ordinately regulated defence against oxidative stress. Free Radic Res. 1999;31:273-300.

38. Yadav AS, Bhatnagar D. Chemoprevantive effect of Star anise in Nnitrosodiethylamine initiated and phenobarbital promoted hepatocarcinogenesis. Chem Biol Interact. 2007:169:207-14.

39. Shacter E. Quantification and significance of protein oxidation in biological samples. Drug Metab Rev. 2000;32:307-26.

40. Beal M. Oxidatively modified proteins in aging and disease. Free Radic Biol Med. 2002;32:797-803.

41. Fernandes L, Sullivan S, Mcfarlane IG, Wojcicka BM, Warnes TW, Eddleston ALWF, Hamilton EBD, Williams R. Studies on the frequency and pathogenesis of liver involvement in rheumatoid arthritis. Ann Rheum Dis. 1979;38:501-6 